\title{
Obituary: Dr Roy E. Rowe
}

It is with great regret we have to record that Dr Roy E. Rowe died on 18 December 2008 aged almost 80. Roy was a member of the Magazine of Concrete Research (MCR) editorial panel for some 25 years (1966-1991) and was instrumental in guiding the magazine's progress that is still relevant today. He led by example, both as Director-General of the UK Cement and Concrete Association (C\&CA; 1977-1987) and before that, as Director of Research (19661977). Roy spent most of his career with C\&CA, having joined the structures department in 1952 following his period at Pembroke College, Cambridge reading mechanical sciences.

His research work was prolific, particularly in the areas of bridge decks, prestressed concrete and, notably, introducing limit-state design into the UK culminating in CP110 in the late 1960s. Such was his approach that the outcomes of research should find their way into improved practices. In becoming President of the Institution of Structural Engineers in 1983, his chosen subject was "to research, communicate and codify - well!"

Roy's influence on and contribution to the reputation and standing of C\&CA was substantial. He was central to raising standards in concrete design and construction. Additionally, the expansion of research activity and the creation of C\&CA as a major training centre and Fulmer Grange, coupled with an extensive regional advisory service, epitomised his approach of sound research transferring to and communicating with practice.

His contribution was recognised by his peers, at home and internationally. He was a Fellow of the Royal Academy of Engineering, Honorary Fellow of the American Concrete Institute and a Foreign Associate of the US Academy of Engineering. As President of the Comité Européen du Béton (CEB; 1987-1998) he had a leading role in the merger of $\mathrm{CEB}$ and the Fédération

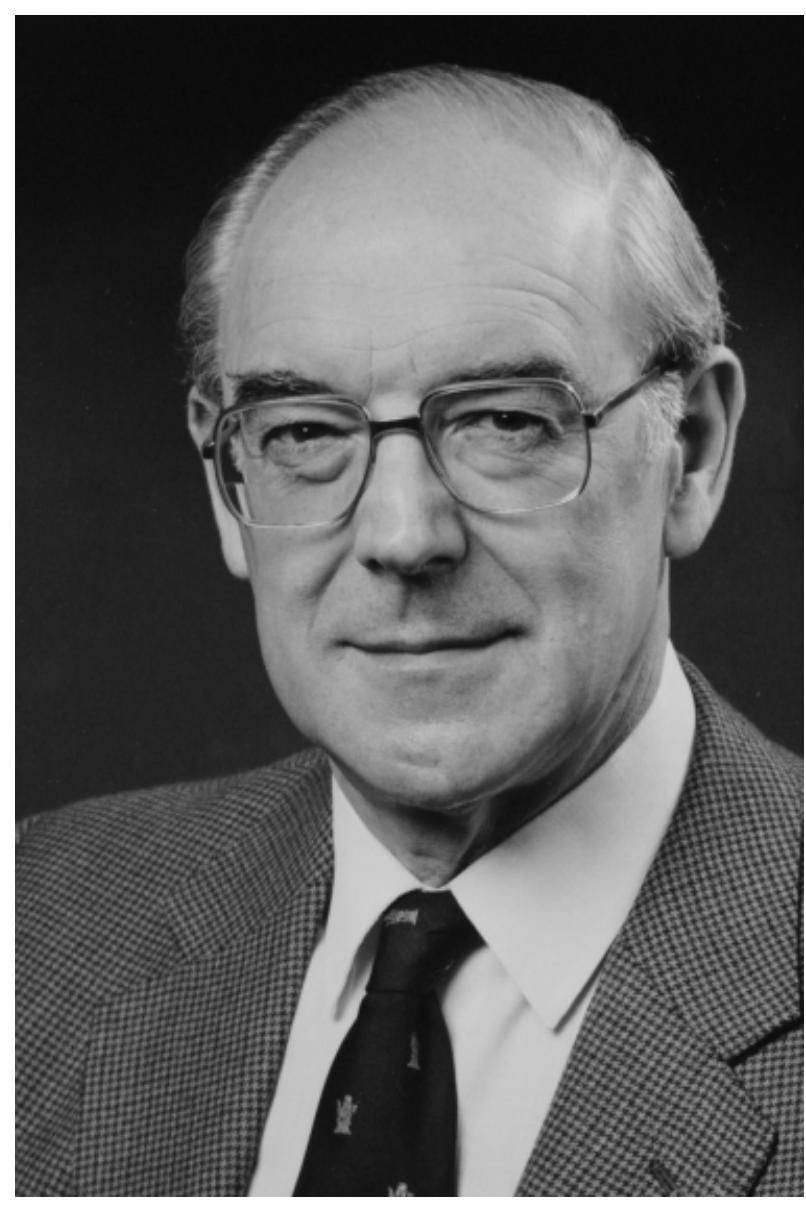

Internationale de la Précontrainte (FIP) to form the present fib. In 1977 he was awarded a CBE.

Our commiserations to his wife, Lilian, his daughter, Fiona, his son-in-law, Simon, and two grand-daughters.

MCR acknowledges Roy's unique contribution to both the magazine and to concrete research globally. 